\title{
Effects of early rumen development and solid feed composition on growth performance and abomasal health in veal calves
}

\author{
H. Berends, ${ }^{\star 1}$ C. G. van Reenen, $\dagger$ N. Stockhofe-Zurwieden, $\neq$ and W. J. J. Gerrits ${ }^{\star}$ \\ ${ }^{*}$ Animal Nutrition Group, Wageningen University, PO Box 338, 6700 AH Wageningen, the Netherlands \\ †Livestock Research, Animal Sciences Group, Wageningen University and Research Centre, PO Box 65, 8200 AB, Lelystad, the Netherlands \\ $\ddagger$ Central Veterinary Institute, Wageningen University and Research Centre, PO Box 65, 8200 AB, Lelystad, the Netherlands
}

\begin{abstract}
The experiment was designed to study the importance of early rumen development and of the composition of solid feed intake on growth performance and abomasal health in milk-fed veal calves. One hundred and six Holstein-Friesian male calves were included in the experiment, and studied during 2 successive 12 -wk periods (period 1 and period 2). In a $2 \times 2$ factorial arrangement, effects of partially replacing milk replacer by solid feed during period 1 and partially replacing dry matter (DM) intake from maize silage and barley straw by concentrate during period 2 were tested. Solid feed during period 1 consisted of maize silage, barley straw, and concentrate (25:25:50 on a DM basis). Solid feed during period 2 consisted of maize silage and barley straw (50:50 ratio on DM basis) for the nonconcentrate groups, and maize silage, barley straw and concentrates (25:25:50 on a DM basis) for the concentrate groups. At the end of period $1(\mathrm{n}=16)$ and at the end of period $2(\mathrm{n}=90)$, parameters of animal performance, rumen development, rumen fermentation, ruminal drinking, and abomasal damage were examined. Partially replacing milk replacer by solid feed during period 1 resulted in early rumen development (ERD) at the end of period 1 , characterized by increased rumen weight, and an increased epithelial and absorptive surface area. Both ERD and partially replacing roughage by concentrates in period 2 increased the rumen development score at the end of period 2. Although ERD calves consumed more solid feed and less milk replacer during period 1 and 2 than non-ERD calves, carcass weight gains at 25 wk were identical, and utilization of the solid feed provided appeared similar to that of milk replacer. Partially replacing roughage by concentrates in period 2 increased dressing percentage and warm carcass weight. Plaque formation at the rumen mucosa was unaffected by ERD or partially replacing roughage by concentrates
\end{abstract}

Received June 21, 2011

Accepted February 6, 2012.

${ }^{1}$ Corresponding author: Harma.Berends@wur.nl and generally low in all calves. The prevalence of large scars in the abomasum in ERD calves was decreased compared with non-ERD calves. This may indicate that ERD provided protection against abomasal lesions. In conclusion, early compared with late rumen development improves feed utilization and may be beneficial for abomasal health.

Key words: veal calf, roughage composition, rumen development, abomasum

\section{INTRODUCTION}

Since 1997, the European Union legislation stipulates provision of a minimum daily amount (50 to $250 \mathrm{~g}$ ) of fibrous feed for veal calves on milk replacer (MR) diets to improve animal health and welfare. As no further specification was made, ingredients like maize silage and straw would both comply with legislation. With increasing prices of MR ingredients, an increasing economic incentive exists to replace MR by fibrous feed, hereafter referred to as solid feed. Solid feed provision has been shown to decrease oral stereotyped behaviors and improve rumen development and rumination (Kooijman et al., 1991; Veissier et al., 1998; Blokhuis et al., 2000), and can affect animal health and performance in both a positive and negative way.

When feeding concentrate feed as the only solid feed source to veal calves, Suárez et al. (2006b, 2007) observed poorly developed rumen mucosa and so-called plaque formation (i.e., patches of focal mucosa inflammation with coalescing and adhering papillae covered by feed particles, hair, and cell debris). In addition, they observed that 21 to $35 \%$ of the ingested milk enters the reticulorumen, rather than the abomasum (Suárez et al., 2007). Excessive ruminal drinking may lead to impaired digestion, metabolic acidosis (Gentile et al., 2004) or villus atrophy (Van Weeren-Keverling Buisman et al., 1990). Furthermore, the provision of roughages to veal calves increased the prevalence of abomasal lesions (Welchman and Baust, 1987; Mattiello et al., 2002; Brscic et al., 2011). Their mechanically abrasive effect in combination with consumption of 
large volumes of milk may cause local ischemia and subsequent focal necrosis (Welchman and Baust, 1987; Breukink et al., 1991).

We hypothesized that poor rumen development deteriorates abomasal health and compromises digestive utilization of solid feed. Optimizing rumen development in veal calves requires information regarding the effects of dose, composition (specifically the concentrate-toroughage ratio), and timing of solid feed provision. Whereas the separate effects of roughage and concentrate intake are well documented in replacement heifers and beef cattle (Žitňan et al., 1998; Coverdale et al., 2004; Hill et al., 2008), information for veal calves is limited to an age of 12 wk (Suárez et al., 2006a,b, 2007) or to selected sources and intake levels (Blokhuis et al., 2000; Cozzi et al., 2002; Labussiere et al., 2009). Due to potential interactions between MR and solid feed, occurring either at the level of digestion or postabsorption, the contribution of solid feed to nutrient supply may differ from that in ruminants exclusively fed concentrates and roughage.

Therefore, the aims of the present study were 1) to investigate the influence of early compared with late rumen development on feed utilization and the incidence of abomasal lesions of veal calves during later life and 2) to investigate the difference between concentrate and roughages on animal performance and abomasal health in veal calves.

\section{MATERIALS AND METHODS}

The experiment was conducted at the experimental farm of Wageningen University and Research Centre in Lelystad, the Netherlands. Experimental procedures complied with the Dutch law on experimental animals.

\section{Animals, Diets, and Observations}

Animals. One hundred and six male HolsteinFriesian veal calves were included in the experiment. Calves were purchased in 2 batches from commercial dairy farms to obtain a uniform group of calves of the same age (average age and BW upon arrival: $12 \pm 0.3$ $\mathrm{d}$ and $46 \pm 0.2 \mathrm{~kg}$, respectively). Within each batch, calves were housed in groups of 5 calves, and groups were randomly assigned to dietary treatments. The experiment consisted of 2 successive 12 -wk periods, period 1 (P1) and period $2(\mathbf{P} 2)$ respectively. Calves were housed in group pens with wooden-slatted floors measuring $3 \times 3 \mathrm{~m}$, without bedding material. During $\mathrm{P} 1$, calves were kept individually in $0.9-\mathrm{m}^{2}$ temporary pens placed inside the group pen, which were removed at the start of P2. Environmental temperature in the stable was maintained at least at $15^{\circ} \mathrm{C}$. Animal health was checked daily by animal care takers. During the first $10 \mathrm{~d}$ after arrival, all calves were treated with oxytetracycline (broad-spectrum antibiotic) and colistin (polypeptide antibiotic). Hemoglobin concentration in blood was monitored across the trial at wk 5, 10, 18, and 24 and corrected to comply with the minimum European Union level of $4.5 \mathrm{mmol} / \mathrm{L}$ at the end of the fattening period.

Dietary Treatments. Dietary treatments are presented in Table 1 . In a $2 \times 2$ factorial arrangement, effects of a partial replacement of MR by solid feed during P1 (early rumen development, ERD), and a partial replacement of DMI from maize silage and straw by concentrate in the diet during P2 (CONC), were tested. Additionally, a reference treatment was included, with partial replacement of MR by solid feed during P1 (ERD) and without any solid feed provision during P2. The reference treatment was included to generate reference values for rumen development, abomasal lesions, and performance at the end of P2, and was excluded from any statistical comparison. All diets were provided on top of an MR diet. During P1 and P2, solid feed intakes were maximized at 750 and $500 \mathrm{~g}$ of $\mathrm{DM} / \mathrm{d}$ in $\mathrm{P} 1$ and P2, respectively. The amount and composition of solid feed, and the duration of P1 (12 wk) were based on previous results of Suárez et al. (2006b, 2007), who observed good rumen development in veal calves at 12 wk of age in a comparable setting. For treatments with solid feed supplementation in P1, milk schemes were reduced to stimulate the intake of solid feed (Table 1). In addition, 16 calves were included in the experiment during P1 and then slaughtered, to provide a reference value for comparison of rumen development at the end of $\mathrm{P} 1$ with other results. These 16 calves were assigned to either an MR diet (non-ERD; $\mathrm{n}=4$ ) or an MR diet partially replaced by solid feed $(\mathrm{ERD} ; \mathrm{n}=12$; Table 1$)$.

The diet was offered to the calves in 2 equal portions (at 0600 and $1600 \mathrm{~h}$ ). Milk replacer was fed individually in buckets. Solid feed sources included maize silage, barley straw, concentrate or a mixture thereof. For the maize silage and straw mixture diets, maize silage and straw were mixed on a 50:50 DM basis. For the maize silage, straw, and concentrate diets, maize silage, straw, and concentrate were mixed on a 25:25:50 DM basis. Ingredient and nutrient compositions of the MR and solid feed sources are presented in Table 2 . The concentrate was provided as pellets and the roughages were chopped. Solid feed was provided individually in buckets during P1. During P2, calves received roughage groupwise in a trough. Intake of solid feed was registered daily per calf during P1 and per group during P2. To avoid selection of dietary components 
Table 1. Experimental design, including milk replacer schemes and solid feed supply during period 1 and 2 for dietary treatments

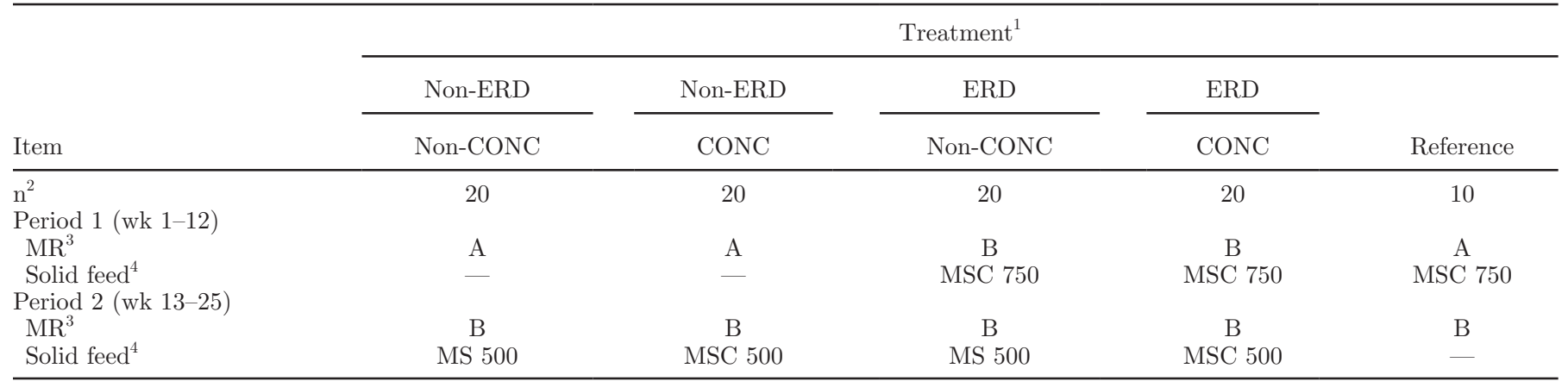

${ }^{1}$ ERD = early rumen development [partial replacement of milk replacer (MR) by solid feed during period 1 (P1, the first of two 12-wk periods)]; $\mathrm{CONC}=$ partial replacement of DMI from maize silage and straw by concentrate in the diet during period 2 (P2). The reference treatment was excluded from any statistical comparison.

${ }^{2}$ This excludes the calves of the non-ERD non-CONC $(\mathrm{n}=4)$ and ERD non-CONC treatment $(\mathrm{n}=12)$ that were slaughtered at the end of P1 to determine rumen development.

${ }^{3}$ Milk replacer: A: milk replacer supply increased from $0.39,0.51,0.72,0.94,1.18,1.40,1.50,1.54,1.65,1.75,1.86$, and $1.99 \mathrm{~kg} / \mathrm{d}$ in wk 1 to 12 , respectively; B: MR supply increased from $0.36,0.46,0.48,0.50,0.59,0.70,0.75,0.88,1.01,1.19,1.40$, and $1.60 \mathrm{~kg} / \mathrm{d}$ in wk 1 to 12 , respectively; and from $1.80,1.80,2.03,2.32,2.46,2.58,2.71,2.85,2.99,3.13,3.20,3.20,3.20$, and $3.20 \mathrm{~kg} / \mathrm{d}$ in wk 13 to 24 , respectively.

${ }^{4}$ Solid feed: MSC $750=750 \mathrm{~g}$ of DM/d of MSC (maize silage, straw, and concentrate mixture 25:25:50 on a DM basis); MS 500 = 500 g of $\mathrm{DM} / \mathrm{d}$ of MS (maize silage:straw = 50:50 on a DM basis); MSC 500: $500 \mathrm{~g}$ of DM/d of MSC. To avoid selective intake of solid feed sources and to minimize orts, the expected DMI was calculated weekly based on the realized DMI in the previous week and a projected weekly increase.

and to minimize orts, the expected DMI was calculated weekly based on the realized DMI during the previous week and a projected weekly increase. During the first 4 wk of P1, milk replacer was reconstituted in the same volume of water for every treatment, and from wk 5 onwards calves were allowed ad libitum access to water for $2 \mathrm{~h}$ around noon.

Slaughter Procedure. At the end of P1, 16 calves were slaughtered to provide a reference for the start of P2. The remaining calves $(n=90)$ were slaughtered at

Table 2. Analyzed nutrient composition of milk replacers, concentrates, and roughages

\begin{tabular}{|c|c|c|c|c|c|c|}
\hline \multirow[b]{2}{*}{ Nutrient $^{1}$} & \multicolumn{2}{|c|}{ Milk replacer } & \multicolumn{2}{|c|}{ Concentrate } & \multirow[b]{2}{*}{ Straw } & \multirow{2}{*}{$\begin{array}{l}\text { Maize } \\
\text { silage }\end{array}$} \\
\hline & $\mathrm{P} 1^{2}$ & $\mathrm{P} 2^{3}$ & $\mathrm{P} 1^{4}$ & $\mathrm{P} 2^{5}$ & & \\
\hline $\mathrm{CP}$ & 218 & 208 & 195 & 171 & 26 & 76 \\
\hline Crude fat & 192 & 213 & 42 & 40 & 9 & 31 \\
\hline Crude ash & 75 & 71 & 34 & 33 & 134 & 38 \\
\hline Starch and sugars & - & - & 333 & 410 & 4 & 306 \\
\hline NDF & - & - & 250 & 217 & 755 & 408 \\
\hline $\mathrm{ADF}$ & - & - & 108 & 87 & 462 & 228 \\
\hline $\mathrm{ADL}$ & - & - & 11 & 10 & 54 & 20 \\
\hline $\mathrm{Ca}$ & 10.2 & 8.6 & 1.4 & 1.9 & 3.4 & 2.2 \\
\hline $\mathrm{P}$ & 7.4 & 6.8 & 4.4 & 4.7 & 0.4 & 1.9 \\
\hline $\mathrm{Fe}, \mathrm{mg} / \mathrm{kg}$ of $\mathrm{DM}$ & 39 & $>15$ & 121 & 132 & 124 & 144 \\
\hline
\end{tabular}

${ }^{1}$ Presented as $\mathrm{g} / \mathrm{kg}$ of DM unless specified otherwise.

${ }^{2}$ Ingredient composition of milk replacer in P1 (period 1): 50\% whey protein concentrate, $26.6 \%$ whey powder, $17.1 \%$ oils and fats, $5 \%$ low lactose whey powder, and 1.3\% premix (provided per kilogram of milk replacer: lactose: $445 \mathrm{~g}$; vitamin A: 25,000 IU; vitamin $\mathrm{D}_{3}: 2,000 \mathrm{IU}$; vitamin E: $80 \mathrm{mg}$; vitamin C: $80 \mathrm{mg}$; Ca: $7.2 \mathrm{~g}$; P: 6.4 g; Na: 4.8 g; K: 13.9 g; Mg: 1.4 g; Zn: 40 mg; Cu: 10 mg; Mn: 30 mg; Se: 0.15 mg; Fe: 39 mg).

${ }^{3}$ Ingredient composition of milk replacer in P2 (period 2): $19 \%$ whey protein concentrate, $36.8 \%$ whey powder, $20.5 \%$ oils and fats, $13.3 \%$ low lactose whey powder, $4 \%$ wheat protein, $2.5 \%$ soy protein concentrate, $2 \%$ starch, $0.3 \%$ L-lysine, $0.2 \%$ DL-methionine, and $1.5 \%$ premix (provided per kilogram of milk replacer: lactose: $410 \mathrm{~g}$; vitamin A: 25,000 IU; vitamin $\mathrm{D}_{3}: 2,000 \mathrm{IU}$; vitamin E: $80 \mathrm{mg}$; vitamin C: $80 \mathrm{mg}$; Ca: $7.9 \mathrm{~g}$; P: $6.3 \mathrm{~g}$; Na: 6.1 g; K: 18.5 g; Mg: 1.4 g; Zn: 80 mg; Cu: 4 mg; Mn: 10 mg; Se: $0.1 \mathrm{mg}$; Fe: 2.8 mg).

${ }^{4}$ Ingredient composition of concentrate in P1: $10 \%$ maize, $20 \%$ maize feed meal, $20 \%$ barley, $5 \%$ oat husk meal, $20 \%$ lupines ( $\mathrm{CF}<70, \mathrm{CP}<335)$, and $25 \%$ malt culms $(\mathrm{CP}<200)$.

${ }^{5}$ Ingredient composition of concentrate in P2: $30 \%$ maize, $10 \%$ maize feed meal, $20 \%$ barley, $20 \%$ lupines (CF $<70, \mathrm{CP}<335)$, and $20 \%$ malt sprouts $(\mathrm{CP}<200)$. 
the end of P2. Calves were transported about $75 \mathrm{~km}$ (ca. $1 \mathrm{~h}$ ) to a slaughter facility and euthanized by stunning (captive bolt pistol) and subsequent exsanguination. Carcasses were weighed. To quantify ruminal drinking (leakage of milk replacer to the rumen), $3.0 \mathrm{~g}$ (P1) or $5.0 \mathrm{~g}$ (P2) of Co, complexed as CoEDTA (prepared according to Udén et al., 1980), was dissolved into the final MR meal, provided 30 min before transport. Time between final MR meal and slaughter averaged $4 \mathrm{~h}(2$ to $6 \mathrm{~h}$ ). To avoid reflux of MR containing CoEDTA from the abomasum into the forestomachs at slaughter, calves were lifted by the forelegs immediately following exsanguination. Subsequently, ligations were made at the level of the thoracic entrance, the omasal-cardia of the abomasum and the reticulo-omasal orifice. The weight of the reticulorumen was recorded with and without contents. Rumen contents were quantitatively collected and solid and liquid phases were separated using a metal sieve $(1.5 \mathrm{~mm})$. A sample of the rumen liquid was used for $\mathrm{pH}$ measurement, acidified with $\mathrm{H}_{3} \mathrm{PO}_{4}(5 \%)$, and stored frozen for analysis of VFA, lactic acid, and ammonia. A reconstituted sample of rumen contents was prepared by proportional sampling of the liquid and solid phases, which was oven dried and stored for Co analysis. Blood samples were taken for analysis of hemoglobin levels. Measurement of carcass weight and visual classification of meat color was performed by a certified employee of the Central Office for Slaughter Livestock Services (BV CBS, Zeist, the Netherlands).

\section{Analytical Procedures}

Calves were weighed every $4 \mathrm{wk}$, and once-per-week samples of MR, diet ingredients, and orts were collected and pooled for analysis of chemical composition.

Ruminal Fluid. Concentrations of VFA and lactic acid were quantified by HPLC as described previously by Suárez et al. (2007). Ammonia concentrations were determined by a modified Berthelot method (Robinson et al., 1986). Rumen Co pool size ( $\mathrm{kg}$ ) was calculated from rumen DM pool $(\mathrm{kg})$ and Co concentration $(\mathrm{mg} /$ $\mathrm{kg}$ of DM); Co recovery was expressed as a percentage of the Co pulsed dose. Cobalt concentration was determined in rumen contents by inductively coupled plasma atomic emission spectroscopy, as described by Suárez et al. (2007).

Rumen Wall Evaluation. The rumen was dissected along the dorsal line, emptied, and rinsed with cold water. The histological assessment and subsequent microscopic examination of rumen mucosa and sites of sampling of the rumen wall for further morphometric analysis were carried out as described by Suárez et al. (2006b). Briefly, the mucosal surface was examined visually and the presence and density of rumen papillae were scored on a 5-point scale from poor to excellent: $1,1.5,2,2.5$, and 3 . The prevalence of plaque formation was assessed visually. The morphometric analyses were conducted in 3 slides cut from a $2 \times 2$-cm section of rumen wall tissue from the saccus ruminis dorsalis, saccus ruminis ventralis, and the atrium of the rumen. The slides were embedded in paraffin and subsequently stained with hematoxylin. Morphometric analyses were performed at a magnification of $2.5 \times$ (Olympus microscope; Olympus Corp., Tokyo, Japan) by using the image analysis software Image Pro Plus (Media Cybernetics Inc., Silver Spring, MD). The measurements for each slide comprised 1) the ratio of mucosa length to serosa length (RMSL) as a measure of the total absorptive surface, which was determined as the length of the mucosal surface within a slide divided by the length of the corresponding serosa (the latter being about $2 \mathrm{~cm}$ ); 2) mucosa thickness, measured at 3 randomly chosen sites per slide; and 3) muscle layer thickness, measured at the same sites as for mucosa thickness.

Abomasal Lesions. The abomasal wall was visually inspected macroscopically for erosions, ulcers, and scars, each in the following size categories: small = modification $<0.5 \mathrm{~cm}^{2}$; medium $=0.5 \mathrm{~cm}^{2}<$ modification $<1.0 \mathrm{~cm}^{2}$; and large $=$ modification $>1.0 \mathrm{~cm}^{2}$.

\section{Statistical Analysis}

Group pens were considered the experimental units and means or percentages per pen were analyzed. The reference treatment was excluded from any statistical comparison. For continuous variables an ANOVA model was used. For percentages, a generalized linear model (GLM) was used, with a logit link and a multiplicative dispersion parameter with respect to the binomial variance function.

Analysis of variance comprised estimation by maximum likelihood and testing by the F-test, assuming normality and equal variances. Logistic regression comprised estimation by maximum quasi-likelihood and testing by the quasi-likelihood ratio test or the Wald test. Dispersion parameters were estimated from the Pearson generalized chi-squared statistic (McCullagh and Nelder, 1989). Analysis of variance or GLM included fixed effects for batches, ERD in P1, CONC, and the interaction between the latter 2 factors. In all analyses, nonsignificant interactions $(P>0.05)$ were excluded from the model.

For several measures (including the prevalence of plaque and prevalence of medium and large abomasal erosions), GLM did not converge due to the presence of 
Table 3. Effects of early rumen development (ERD) in period 1 on macroscopic and microscopic parameters of the rumen mucosa in veal calves, determined at the end of period 1 (12 wk)

\begin{tabular}{|c|c|c|c|}
\hline \multirow[b]{2}{*}{ Item } & \multicolumn{2}{|c|}{ Dietary treatment ${ }^{1}$} & \multirow[b]{2}{*}{ SEM } \\
\hline & Non-ERD & ERD & \\
\hline $\mathrm{n}$ & 4 & 12 & \\
\hline \multicolumn{4}{|l|}{ Macroscopic parameter } \\
\hline Empty rumen weight, $\mathrm{g}$ & $668^{\mathrm{b}}$ & $1,018^{\mathrm{a}}$ & 52.2 \\
\hline Rumen development ${ }^{2}$ & 1.0 & 1.5 & - \\
\hline Rumen plaque, $\%$ of calves & 0 & 0 & - \\
\hline Rumen Co recovery, \% & 22 & 10 & 4.3 \\
\hline \multicolumn{4}{|l|}{ Microscopic parameter } \\
\hline \multicolumn{4}{|l|}{ Rumen dorsal location } \\
\hline RMSL $^{3}$ & $2.2^{\mathrm{b}}$ & $3.9^{\mathrm{a}}$ & 0.38 \\
\hline Mucosa thickness, $\mu \mathrm{m}$ & $286^{\mathrm{b}}$ & $898^{\mathrm{a}}$ & 125.7 \\
\hline Muscle thickness, $\mu \mathrm{m}$ & 1,292 & 1,700 & 253 \\
\hline \multicolumn{4}{|l|}{ Rumen ventral location } \\
\hline RMSL & 3.9 & 5.4 & 0.56 \\
\hline Mucosa thickness, $\mu \mathrm{m}$ & 1,084 & 1,210 & 153.0 \\
\hline Muscle thickness, $\mu \mathrm{m}$ & 1,408 & 1,714 & 219.7 \\
\hline \multicolumn{4}{|l|}{ Rumen atrium } \\
\hline RMSL & $4.7^{\mathrm{b}}$ & $7.7^{\mathrm{a}}$ & 0.71 \\
\hline Mucosa thickness, $\mu \mathrm{m}$ & 1,271 & 1,786 & 195.3 \\
\hline Muscle thickness, $\mu \mathrm{m}$ & 2,276 & 2,596 & 192.0 \\
\hline
\end{tabular}

${ }^{\mathrm{a}, \mathrm{b}}$ Means in the same row with different superscripts differ $(P<0.01)$.

${ }^{1}$ Dietary treatments were as follows: Non-ERD $=$ milk replacer only: milk replacer supply increased from $0.39,0.51,0.72,0.94,1.18,1.40$, $1.50,1.54,1.65,1.75,1.86$, and $1.99 \mathrm{~kg} / \mathrm{d}$ in wk 1 to 12 , respectively; $\mathrm{ERD}=$ partial replacement of milk replacer by solid feed. Solid feed supply of $750 \mathrm{~g}$ of DM/d of MSC (maize silage, straw, and concentrate mixture, 25:25:50 on a DM basis) on top of a milk replacer diet: milk replacer supply increased from $0.36,0.46,0.48,0.50,0.59,0.70,0.75$, $0.88,1.01,1.19,1.40$, and $1.60 \mathrm{~kg} / \mathrm{d}$ in wk 1 to 12 , respectively.

${ }^{2}$ Average of a discrete examination scale of 5 scores from poor to excellent: $1,1.5,2,2.5$, and 3 .

${ }^{3} \mathrm{RMSL}=$ ratio of mucosa to serosa length. too many zeros in the data. In these cases, the Fisher exact test was used as an approximate test to examine differences between treatment groups. All calculations were performed with GenStat (Genstat Committee, 2000).

\section{RESULTS}

\section{Characterization of Calves at 12 wk (P1)}

The results on macroscopic and microscopic rumen development are presented in Table 3. Empty rumen weight was increased significantly in ERD calves $(P<$ 0.01 ). The RMSL in both the rumen atrium and the dorsal location was increased in ERD calves $(P<0.01)$. Ruminal plaque formation was not observed at $12 \mathrm{wk}$ (Table 3). During P1, the ADG of non-ERD calves was $12 \%$ higher than the ADG of calves supplemented with solid feed $(P<0.001$; Table 4$)$. The feed conversion ratio (FCR) was lower in non-ERD when compared with ERD calves $(P<0.001)$.

\section{Feed Intake and Growth Performance}

The least squares means of DMI, ADG, and FCR are presented in Table 4. Compared with non-ERD calves, ERD calves showed an increase in ADG of $100 \mathrm{~g} / \mathrm{d}(P$ $<0.05)$ during $\mathrm{P} 2$ and a tendency toward a lower FCR $(P<0.10)$. The CONC increased dressing percentage $(P<0.01)$ and carcass weight $(P<0.05)$. No effect of dietary treatment on carcass fat retention was observed (results not shown).

Table 4. Effects of early rumen development (ERD) and inclusion of concentrate in the solid feed mixture in period 2 (CONC) on performance parameters in veal calves ${ }^{1}$

\begin{tabular}{|c|c|c|c|c|c|c|c|c|c|}
\hline \multirow[b]{2}{*}{ Item } & \multicolumn{2}{|c|}{ Period 1} & \multicolumn{2}{|c|}{ Period 2} & \multirow[b]{2}{*}{ SEM } & \multirow{2}{*}{$\begin{array}{c}\begin{array}{c}\text { ERD } \\
\text { effect }^{1}\end{array} \\
P \text {-value }\end{array}$} & \multirow{2}{*}{$\begin{array}{c}\begin{array}{c}\text { CONC } \\
\text { effect }^{1}\end{array} \\
P \text {-value }\end{array}$} & \multirow[b]{2}{*}{ Reference } & \multirow[b]{2}{*}{ SEM } \\
\hline & $\begin{array}{l}\text { Non- } \\
\text { ERD }\end{array}$ & ERD & $\begin{array}{l}\text { Non- } \\
\text { CONC }\end{array}$ & $\mathrm{CONC}$ & & & & & \\
\hline \multicolumn{10}{|l|}{ Period 1 (wk 1-12) } \\
\hline DMI milk replacer, kg & 106.8 & 69.2 & & & 0.27 & $* * *$ & & & \\
\hline DMI solid feed, $\mathrm{kg}$ & 0 & 44.3 & & & 1.59 & $* * *$ & & & \\
\hline \multicolumn{10}{|l|}{ Period 2 (wk 13-24) } \\
\hline DMI of milk replacer, $\mathrm{kg}$ & 243.4 & 241.2 & 240.8 & 243.8 & 3.87 & - & - & 232.5 & 7.43 \\
\hline DMI of solid feed, $\mathrm{kg}$ & 41.6 & 45.3 & 42.8 & 44.1 & 1.22 & - & - & 0.0 & - \\
\hline $\mathrm{ADG}, \mathrm{g} / \mathrm{d}$ & 1,470 & 1,572 & 1,490 & 1,552 & 33.2 & $*$ & NS & 1,284 & 63.7 \\
\hline $\mathrm{FCR}, \mathrm{kg} / \mathrm{kg}$ & 2.09 & 1.97 & 2.06 & 1.99 & 0.047 & $\dagger$ & NS & 1.97 & 0.089 \\
\hline Dressing percentage, \% & 55.1 & 54.4 & 54.3 & 55.2 & 0.21 & $\dagger$ & ** & 54.4 & 0.46 \\
\hline Warm carcass weight, $\mathrm{kg}$ & 138 & 138 & 135 & 141 & 1.8 & NS & $*$ & 123 & 3.5 \\
\hline
\end{tabular}

${ }^{1}$ No interactions between ERD and CONC were found $(P>0.05)$.

${ }^{2}$ Feed conversion ratio.

$\dagger P \leq 0.10 ;{ }^{*} P \leq 0.05 ;{ }^{* *} P \leq 0.01 ;{ }^{* * *} P \leq 0.001$. 
At the end of P2, hemoglobin levels were in the range of 5.0 to $5.4 \mathrm{mmol} / \mathrm{L}$ (SEM 0.11) for treatments with solid feed provision in $\mathrm{P} 2$, and the average hemoglobin level for reference calves was $4.9 \mathrm{mmol} / \mathrm{L}$ (SEM 0.20). Early rumen development coincided with an increase in hemoglobin level (5.4 vs. $5.0 \mathrm{mmol} / \mathrm{L}$ for ERD vs. non-ERD; $P<0.05$ ). Meat color was assessed visually on a discrete scale. Average meat color values ranged between 4.4 and 4.8 (SEM 0.14; results not shown) with an average score for reference calves of 4.4 (SEM 0.25). Meat color was not affected by ERD or CONC.

\section{Rumen Fermentation Parameters}

The effects of dietary treatments on rumen fermentation parameters are shown in Table 5. The CONC increased molar proportions of butyrate, valerate, and methyl butyrate $(P<0.001)$ at the expense of acetate $(P<0.01)$. Lactate concentrations were unaffected by the dietary treatments. In comparison with roughage only, CONC significantly increased ammonia concentrations $(P<0.01)$, and decreased $\mathrm{pH}(P<0.01)$. The weight of fresh reticulorumen contents at slaughter was affected by ERD, but not by CONC. The CONC increased Co recovery from 13.5 to $18.4 \%(P<0.05)$. Early rumen development did not affect Co recovery at the end of P2.

\section{Macroscopic and Microscopic Evaluation of the Rumen Wall}

An overview of macroscopic and microscopic rumen wall parameters determined after P2 are shown in Table 6. The macroscopic rumen development score was higher in ERD compared with non-ERD calves $(P$ $<0.001)$, and increased with CONC $(P<0.05)$. However, this did not coincide with significant changes in morphometric measures of rumen development, which exhibited large variation.

Empty rumen weight was unaffected by ERD or CONC. The prevalence of plaque formation numerically increased from 10 to $22 \%$ of the calves by CONC. Rumen plaque formation was not observed in calves fed the reference diet.

\section{Abomasal Lesions}

The effects of dietary treatments on abomasal lesions is shown in Table 7 . In general, great variation existed in the prevalence of abomasal lesions. Early rumen development did not affect the percentage of calves with abomasal erosions or ulcers at the end of P2. However, ERD significantly decreased the prevalence of large scars at the end of P2 (6 vs. $20 \%$ for ERD vs. nonERD, $P<0.05)$. Furthermore, CONC resulted in a higher percentage of calves with small scars $(P<0.05)$.

\section{DISCUSSION}

\section{Feed Intake and Growth Performance}

The reduced ADG during P1 for ERD calves may be caused by the difference in digestibility between solid feed and MR (Labussiere et al., 2009), and possibly by the energy required for rumen development. The initiation of solid feed intake and the subsequent ruminal

Table 5. Effects of early rumen development (ERD) and inclusion of concentrate in the solid feed mixture in period 2 (CONC) on rumen (fermentation) parameters in veal calves, determined at the end of period $2^{1}$

\begin{tabular}{|c|c|c|c|c|c|c|c|c|c|}
\hline \multirow[b]{2}{*}{ Item } & \multicolumn{2}{|c|}{ Period 1} & \multicolumn{2}{|c|}{ Period 2} & \multirow[b]{2}{*}{ SEM } & \multirow{2}{*}{$\begin{array}{c}\begin{array}{c}\text { ERD } \\
\text { effect }^{1}\end{array} \\
P \text {-value }\end{array}$} & \multirow{2}{*}{$\begin{array}{l}\begin{array}{l}\text { CONC } \\
\text { effect }^{1}\end{array} \\
P \text {-value }\end{array}$} & \multirow[b]{2}{*}{ Reference } & \multirow[b]{2}{*}{ SEM } \\
\hline & $\begin{array}{l}\text { Non- } \\
\text { ERD }\end{array}$ & ERD & $\begin{array}{l}\text { Non- } \\
\text { CONC }\end{array}$ & CONC & & & & & \\
\hline $\begin{array}{l}\text { Total VFA, mmol/L } \\
\text { Individual FA. mol } / 100 \mathrm{~mol}\end{array}$ & 78 & 77 & 73 & 81 & 4.3 & NS & NS & 38 & 7.5 \\
\hline Acetate & 65.2 & 65.4 & 67.1 & 63.2 & 0.85 & NS & $* *$ & 69.6 & 1.58 \\
\hline Isobutyrate & 1.3 & 1.3 & 1.3 & 1.3 & 0.07 & NS & NS & 2.7 & 0.19 \\
\hline Methyl butyrate & 2.3 & 2.6 & 2.2 & 2.8 & 0.10 & NS & *** & 3.0 & 0.21 \\
\hline Valerate & 1.6 & 1.4 & 1.3 & 1.8 & 0.09 & NS & *** & 0.8 & 0.12 \\
\hline Lactate, $\mathrm{mmol} / \mathrm{L}$ & 3.3 & 2.4 & 1.8 & 3.9 & 2.9 & NS & NS & 7.6 & 5.2 \\
\hline Ammonia, $\mathrm{mmol} / \mathrm{L}$ & 12.8 & 14.7 & 11.0 & 16.5 & 1.36 & NS & ** & 19.3 & 2.39 \\
\hline $\mathrm{pH}$ & 5.9 & 5.9 & 6.1 & 5.7 & 0.08 & NS & ** & 6.2 & 0.14 \\
\hline Weight of fresh rumen contents, $\mathrm{kg}$ & 13.6 & 15.9 & 15.5 & 14.0 & 0.74 & $*$ & NS & 12.3 & 1.30 \\
\hline
\end{tabular}

${ }^{1}$ No interactions between ERD and CONC were found $(P>0.05)$.

$\dagger P \leq 0.10 ;{ }^{*} P \leq 0.05 ;{ }^{* *} P \leq 0.01$; *** $P \leq 0.001$. 
Table 6. Effects of early rumen development (ERD) and inclusion of concentrate in the solid feed mixture in period 2 (CONC) on macroscopic and microscopic parameters of the rumen mucosa in veal calves, at the end of period $2^{1}$

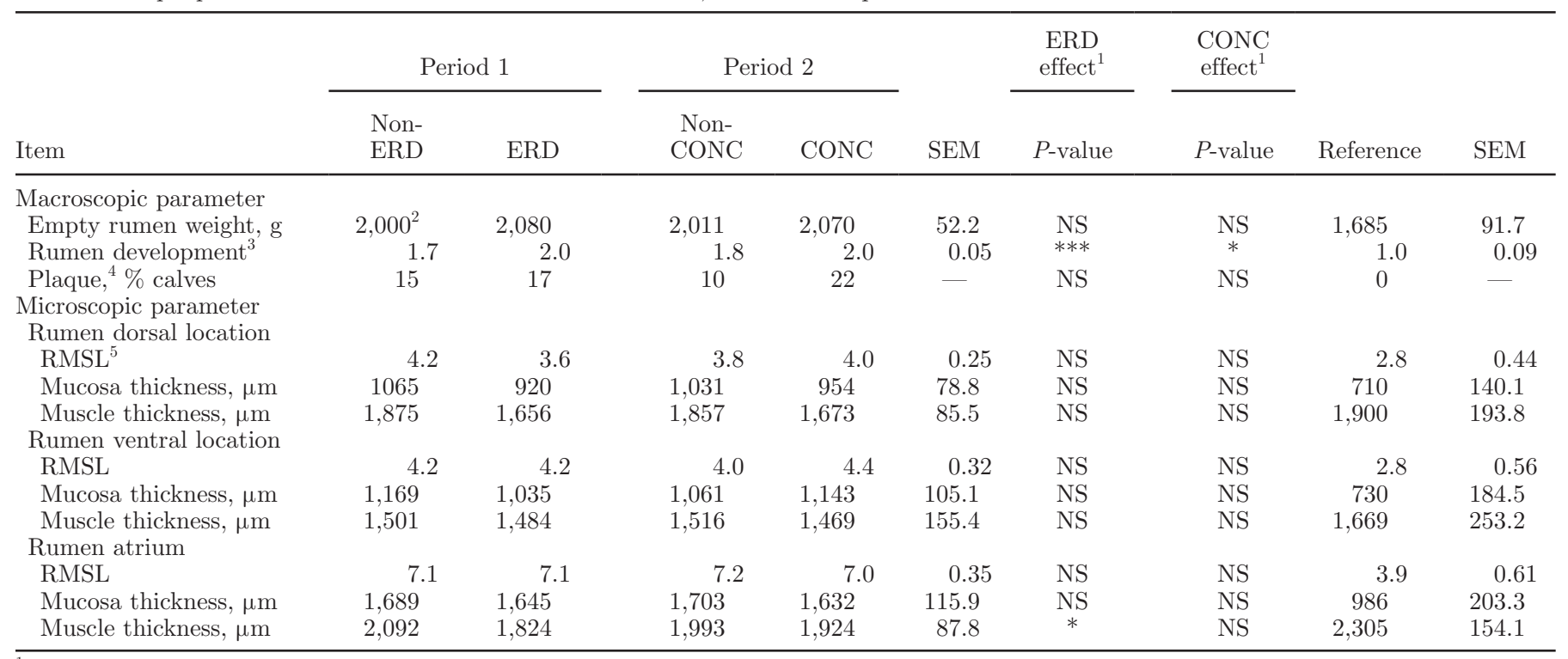

${ }^{1}$ No interactions between ERD and CONC were found $(P>0.05)$.

${ }^{2}$ Predicted means of ANOVA models are presented in the table, unless specified otherwise.

${ }^{3}$ Average of a discrete examination scale of 5 scores from poor to excellent: 1, 1.5, 2, 2.5, and 3 .

${ }^{4}$ Actual percentages are given. Differences between treatment groups were examined with the Fisher exact test.

${ }^{5} \mathrm{RMSL}=$ ratio of mucosa to serosa length.

$\dagger P \leq 0.10 ;{ }^{*} P \leq 0.05 ; * * P \leq 0.01 ; * * * P \leq 0.001$

fermentation resulted in an increase in rumen tissue mass and papillae growth, as was also shown previously (Sander et al., 1959; Baldwin et al., 2004; Suárez et al., 2006b, 2007). This process requires energy but enables the animal to cope with a different supply of dietary substrates. Our study shows that this investment in rumen development during the first weeks is beneficial during the late fattening period, as demonstrated

Table 7. Effects of early rumen development (ERD) and inclusion of concentrate in the solid feed mixture in period 2 (CONC) on the prevalence of abomasal lesions in veal calves at the end of period $2^{1}$

\begin{tabular}{|c|c|c|c|c|c|c|c|c|}
\hline \multirow[b]{2}{*}{ Item } & \multicolumn{2}{|c|}{ Period 1} & \multicolumn{2}{|c|}{ Period 2} & \multirow[b]{2}{*}{ SEM } & \multirow{2}{*}{$\begin{array}{c}\begin{array}{c}\text { ERD } \\
\text { effect }^{1}\end{array} \\
P \text {-value }\end{array}$} & \multirow{2}{*}{$\begin{array}{l}\begin{array}{l}\text { CONC } \\
\text { effect }^{1}\end{array} \\
P \text {-value }\end{array}$} & \multirow[b]{2}{*}{ Reference $^{2}$} \\
\hline & $\begin{array}{l}\text { Non- } \\
\text { ERD }\end{array}$ & ERD & $\begin{array}{l}\text { Non- } \\
\text { CONC }\end{array}$ & $\mathrm{CONC}$ & & & & \\
\hline Erosions, $\%$ of calves & $48^{3}$ & 38 & 50 & 35 & 6.5 & NS & NS & 40 \\
\hline Small $\left(<0.5 \mathrm{~cm}^{2}\right)$ & 45 & 38 & 50 & 32 & 6.6 & NS & $\dagger$ & 40 \\
\hline $\operatorname{Medium}^{4}\left(0.5-1 \mathrm{~cm}^{2}\right)$ & 5 & 3 & 5 & 3 & - & NS & NS & 0 \\
\hline Medium $\left(0.5-1 \mathrm{~cm}^{2}\right)$ & 13 & 21 & 18 & 15 & 6.3 & NS & NS & 0 \\
\hline Large $\left(>1.0 \mathrm{~cm}^{2}\right)$ & 10 & 11 & 13 & 9 & 4.5 & NS & NS & 10 \\
\hline Scars, $\%$ of calves & 78 & 83 & 73 & 89 & 5.3 & NS & NS & 90 \\
\hline Small $\left(<0.5 \mathrm{~cm}^{2}\right)$ & 63 & 74 & 60 & 77 & 4.4 & $\dagger$ & * & 70 \\
\hline Medium $\left(0.5-1 \mathrm{~cm}^{2}\right)$ & 20 & 27 & 18 & 30 & 6.9 & NS & NS & 30 \\
\hline Large $\left(>1.0 \mathrm{~cm}^{2}\right)$ & 20 & 6 & 13 & 14 & 3.5 & * & NS & 10 \\
\hline
\end{tabular}

${ }^{1}$ No interactions between ERD and CONC were found $(P>0.05)$.

${ }^{2}$ All data for the reference group are actual percentages (without SEM).

${ }^{3}$ Predicted means of generalized linear models are presented in the table, unless specified otherwise.

${ }^{4}$ Actual percentages (without SEM) are given. Differences between treatment groups were examined with the Fisher exact test.

$\dagger P \leq 0.10 ;{ }^{*} P \leq 0.05 ;{ }^{*} P \leq 0.01 ;{ }^{* * *} P \leq 0.001$. 
by the significant increase in ADG of $100 \mathrm{~g} / \mathrm{d}$ and a tendency toward a lower FCR in ERD compared with non-ERD calves during P2. As the increased growth rate in $\mathrm{P} 2$ followed a period of decreased growth rate in P1, it may be referred to as compensatory gain, in part related to gastrointestinal contents, and increased mass of gastrointestinal tissues. However, as carcass gain over the entire 25-wk period was identical for ERD and non-ERD calves, it is clear that calf performance actually benefits from ERD. During the entire 25-wk period, a cumulative quantity of $42 \mathrm{~kg}$ of MR DM was exchanged for $48 \mathrm{~kg}$ of solid feed DM (ERD vs. nonERD). When assuming digestible energy (DE) values for MR (4.7 MCal $/ \mathrm{kg}$ of DM, Van den Borne et al., 2006) and the solid feed mixture containing 50:25:25 of concentrate, maize silage, and straw (3.4, 3.2, and 1.8 $\mathrm{MCal} / \mathrm{kg}$ of $\mathrm{DM}$, respectively, from beef cattle data, NRC, 2000), $196 \mathrm{MCal}$ of DE from milk replacer was exchanged by $140 \mathrm{MCal}$ of DE from solid feed, leading to similar carcass weight gain. It illustrates that important interactions may occur between MR and solid feed in veal calves, which warrants further investigation.

\section{Rumen Development}

The rumen development score at the end of $\mathrm{P} 2$ was increased by ERD and CONC. Our observations support earlier findings that enlargement of absorptive surface area is triggered by end products of microbial fermentation (Tamate et al., 1962). Confirming earlier observations by Harrison et al. (1960), when the solid feed supply was stopped during P2, both macroscopic and microscopic parameters were markedly decreased at the end of P2 to levels comparable to those observed in calves exclusively fed MR and slaughtered after P1.

Furthermore, morphometric parameters were measured at 3 locations and considerable differences in muscle thickness, mucosa thickness, and RMSL between these locations were observed. Values found at dorsal and ventral locations are in close agreement with previous results of Suárez et al. (2006b; 2007) in veal calves of 8 to 12 wk. Values for RMSL and mucosa thickness were much higher in the rumen atrium, indicating that the rumen atrium is a major site of absorption. This is also supported by Kristensen et al. (2007), who observed the largest papillae length in the rumen atrium compared with the saccus ruminis ventralis in dairy calves.

Except for the difference in rumen development between calves supplemented with solid feed compared with calves fed MR alone at the end of $\mathrm{P} 1$ and $\mathrm{P} 2$, differences in macroscopic rumen development did not match those in morphometric observations at the end of P2. Variation in morphometric parameters was similar to previous results of Suárez et al. (2006b, 2007). Their observations showed a higher response of morphometric parameters to concentrate composition than roughageto-concentrate ratio.

\section{Rumen and Abomasal Health}

At the end of $\mathrm{P} 1$, plaque formation was not observed, in contrast to previous results of Suárez et al. (2006b), who observed plaque formation in 73 to $100 \%$ of the calves in their study. Their calves, however, were fed concentrate as the only solid feed source, and in subsequent studies, increasing the roughage proportion in the diet was shown to be effective in decreasing plaque formation (Suárez et al., 2007; Brscic et al., 2011). After P2, plaque formation was still generally low compared with previous results (Suárez et al., 2007; Brscic et al., 2011), but this can be explained by the high roughageto-concentrate ratio of the solid feed mixture in the current study.

Suárez et al. (2007) were the first to gather quantitative information on ruminal drinking in calves fed concentrate or roughage, using Co-EDTA as a marker. They observed that $3 \mathrm{~h}$ after feeding, 21 to $35 \%$ of the ingested milk was present in the reticulorumen, rather than the abomasum. The results of the current study showed large interindividual variation. In several calves slaughtered at the end of P1 (1 out of 4 nonERD calves and 4 out of 12 ERD calves), no Co was recovered in the rumen contents. Higher Co recoveries observed by Suárez et al. (2007) may be caused by the higher proportion of concentrate feed in their study. Indeed, our results showed that CONC resulted in a significant increase in Co recovery. Furthermore, the increase in time between the last meal and slaughter and transport of the current study may have affected Co recovery as well.

Veal calves show a high prevalence of abomasal lesions, in the range of 48 to $74 \%$ of calves (Gottardo et al., 2002; Mattiello et al., 2002; Brscic et al., 2011). Multiple factors have been associated with abomasal ulcers in bovine, including abomasal hyperacidity (Ahmed et al., 2002) and the presence of Clostridia and Campylobacter species (Mills et al., 1990; Jelinski et al., 1995). In addition, the interaction between solid feed and a MR diet seems to be particularly relevant for milk-fed calves. In several studies, provision of solid feed to milk-fed veal calves was demonstrated to increase the prevalence of abomasal lesions, including pyloric ulcers, when compared with calves fed MR alone (Breukink et al., 1991; Mattiello et al., 2002; Brscic et al., 2011). These findings may be explained by solid feed particles exerting mechanically abrasive effects on the abomasal mucosa, which may be sensitized due 
to overfilling when large volumes of MR are provided. Promoting rumen development and, consequently, stimulating the fermentative degradation of potentially sharp particles would then reduce this problem. In the present study, ERD did not affect the prevalence of abomasal erosions and ulcers recorded at slaughter, but the prevalence of large scars in ERD calves was significantly decreased compared with non-ERD calves (6\% vs. $20 \%$ ). This suggests that ERD provided some protection against abomasal lesions, probably at the time of transition between P1 and P2. The observed decrease in the prevalence of large scars in ERD calves supports the hypothesis that rumen development is positively related to abomasal health.

\section{CONCLUSIONS}

Both ERD and CONC increased rumen development score at the end of P2. At 25 wk, early rumen development (ERD, starting in wk 1) in veal calves was observed to yield comparable carcass weight to late rumen development (i.e., after 12 wk). Over the 25-wk period, the utilization of the solid feed provided appeared surprisingly similar to that of MR. Partially replacing roughage by concentrates in $\mathrm{P} 2$ increased dressing percentage and warm carcass weight. Plaque formation was generally low in all calves, which may be due to the relatively high roughage-to-concentrate ratio of the solid feed mixture. The prevalence of large scars in ERD calves was significantly decreased compared with non-ERD calves. This may indicate that ERD provided some protection against abomasal lesions. In conclusion, early compared with late rumen development resulted in improved feed utilization and may be beneficial for abomasal health.

\section{ACKNOWLEDGMENTS}

This study was financially supported by the Product Board of Animal Feed (Den Haag, the Netherlands) and the Dutch Ministry of Economic Affairs, Agriculture and Innovation (Den Haag, the Netherlands). Skilled technical assistance of Leonie Heutinck and Joyce van Delen (Livestock Research, Animal Sciences Group, Wageningen University and Research Centre, Lelystad, the Netherlands) is gratefully acknowledged.

\section{REFERENCES}

Ahmed, A. F., P. D. Constable, and N. A. Misk. 2002. Effect of feeding frequency and route of administration on abomasal luminal $\mathrm{pH}$ in dairy calves fed milk replacer. J. Dairy Sci. 85:1502-1508.

Baldwin, R. L. VI, K. R. McLeod, J. L. Klotz, and R. N. Heitmann. 2004. Rumen development, intestinal growth and hepatic metabo- lism in the pre- and postweaning ruminant. J. Dairy Sci. 87(E Suppl.):E55-E65.

Blokhuis, H. J., C. G. van Reenen, J. J. Heeres, L. F. M. Heutinck, A M. van Vuuren, N. Stockhofe, A. E. van de Braak, J. J. de Groot, I. Veissier, B. J. Lensink, L. Florand, M. S. Cockram, G. Cozzi, F. Gottardo, M. Verga, S. Mattiello, E. Canali, S. Raussi, M. Pyykkönen, H. Saloniemi, H. Hepola, and L. Hänninen. 2000. Chain management of veal calf welfare. Final report. European Union project, Contract Number FAIR 3 PL96-2049.

Breukink, H. J., T. Wensing, and J. M. Mouwen. 1991. Abomasal ulcers in veal calves: Pathogenesis and prevention. Pages 118-122 in Proc. Int. Symp. Veal Calf Prod. Pudoc Wageningen, Wageningen, the Netherlands.

Brscic, M., L. F. M. Heutinck, M. Wolthuis-Fillerup, N. Stockhofe, B. Engel, E. K. Visser, F. Gottardo, E. A. M. Bokkers, B. J. Lensink, G. Cozzi, and G. C. Van Reenen. 2011. Prevalence of gastrointestinal disorders recorded at postmortem inspection in white veal calves and associated risk factors. J. Dairy Sci. 94:853-863.

Coverdale, J. A., H. D. Tyler, J. D. Quigley III, and J. A. Brumm. 2004. Effect of various levels of forage and form of diet on rumen development and growth in calves. J. Dairy Sci. 87:2554-2562.

Cozzi, G., F. Gottardo, S. Mattiello, E. Canali, E. Scanziani, M. Verga, and I. Andrighetto. 2002. The provision of solid feeds to veal calves: I. Growth performance, forestomach development, and carcass and meat quality. J. Anim. Sci. 80:357-366.

Genstat Committee. 2000. Reference Manual. Procedure Library PL12. R. G. Payne and G. M. Arnold, ed. VSN International, Oxford, UK

Gentile, A., S. Sconza, I. Lorenz, G. Otranto, G. Rademacher, P. Famigli-Bergamini, and W. Klee. 2004. D-Lactic acidosis in calves as a consequence of experimentally induced ruminal acidosis. J. Vet. Med. A Physiol. Pathol. Clin. Med. 51:64-70.

Gottardo, F., S. Mattiello, G. Cozzi, E. Canali, E. Scanziani, L. Ravarotto, V. Ferrante, M. Verga, and I. Andrighetto. 2002. The provision of drinking water to veal calves for welfare purposes. J Anim. Sci. 80:2362-2372.

Harrison, H. N., R. G. Warner, E. G. Sander, and J. K. Loosli. 1960 Changes in the tissue and volume of the stomachs of calves following the removal of dry feed or consumption of inert bulk. J. Dairy Sci. 43:1301-1312.

Hill, T. M., H. G. Bateman Ii, J. M. Aldrich, and R. L. Schlotterbeck. 2008. Effects of feeding different carbohydrate sources and amounts to young calves. J. Dairy Sci. 91:3128-3137.

Jelinski, M. D., C. S. Ribble, M. Chirino-Trejo, E. G. Clark, and E. D. Janzen. 1995. The relationship between the presence of Helicobacter pylori, Clostridium perfringens type A, Campylobacter spp, or fungi and fatal abomasal ulcers in unweaned beef calves. Can. Vet. J. 36:379-382.

Kooijman, J., H. K. Wierenga, and P. R. Wiepkema. 1991. Development of abnormal oral behaviour in group-housed veal calves: Effects of roughage supply. Page 54-58 in New Trends in Veal Calf Production. Proc. Int. Symp. Veal Calf Prod., Wageningen, the Netherlands. EAAP Publ. No. 52. Pudoc, Wageningen, the Netherlands.

Kristensen, N. B., J. Sehested, S. K. Jensen, and M. Vestergaard 2007. Effect of milk allowance on concentrate intake, ruminal environment, and ruminal development in milk-fed Holstein calves. J. Dairy Sci. 90:4346-4355.

Labussiere, E., S. Dubois, J. van Milgen, G. Bertrand, and J. Noblet. 2009. Effect of solid feed on energy and protein utilization in milkfed veal calves. J. Anim. Sci. 87:1106-1119.

Mattiello, S., E. Canali, V. Ferrante, M. Caniatti, F. Gottardo, G Cozzi, I. Andrighetto, and M. Verga. 2002. The provision of solid feeds to veal calves: II. Behavior, physiology, and abomasal damage. J. Anim. Sci. 80:367-375.

McCullagh, P., and J. A. Nelder. 1989. Generalized Linear Models. 2nd ed. Chapman \& Hall, London, UK.

Mills, K. W., J. L. Johnson, R. L. Jensen, L. F. Woodard, and A R. Doster. 1990. Laboratory findings associated with abomasal ulcers/tympany in range calves. J. Vet. Diagn. Invest. 2:208-212. 
NRC. 2000. Nutrient Requirements of Beef Cattle. 7th rev. ed. Natl. Acad. Sci., Washington, DC.

Robinson, P. H., S. Tamminga, and A. M. van Vuuren. 1986. Influence of declining level of feed intake and varying the proportion of starch in the concentrate on rumen fermentation in dairy cows. Livest. Prod. Sci. 15:173-189.

Sander, E. G., R. G. Warner, H. N. Harrison, and J. K. Loosli. 1959. The stimulatory effect of sodium butyrate and sodium propionate on the development of rumen mucosa in the young calf. J. Dairy Sci. 42:1600-1605.

Suárez, B. J., C. G. Van Reenen, G. Beldman, J. van Delen, J. Dijkstra, and W. J. J. Gerrits. 2006a. Effects of supplementing concentrates differing in carbohydrate composition in veal calf diets: I. Animal performance and rumen fermentation characteristics. J. Dairy Sci. 89:4365-4375.

Suárez, B. J., C. G. Van Reenen, W. J. J. Gerrits, N. Stockhofe, A. M. van Vuuren, and J. Dijkstra. 2006b. Effects of supplementing concentrates differing in carbohydrate composition in veal calf diets: II. Rumen development. J. Dairy Sci. 89:4376-4386.

Suárez, B. J., C. G. Van Reenen, N. Stockhofe, J. Dijkstra, and W. J. J. Gerrits. 2007. Effect of roughage source and roughage to concentrate ratio on animal performance and rumen development in veal calves. J. Dairy Sci. 90:2390-2403.

Tamate, H., A. D. McGilliard, N. L. Jacobson, and R. Getty. 1962. Effect of various dietaries on the anatomical development of the stomach in the calf. J. Dairy Sci. 45:408-420.
Udén, P., P. E. Colucci, and P. J. Van Soest. 1980. Investigation of chromium, cerium and cobalt as markers in digesta. Rate of passage studies. J. Sci. Food Agric. 31:625-632.

Van den Borne, J. J. G. C., M. W. A. Verstegen, S. J. J. Alferink, R. M. M. Giebels, and W. J. J. Gerrits. 2006. Effects of feeding frequency and feeding level on nutrient utilization in heavy preruminant calves. J. Dairy Sci. 89:3578-3586.

Van Weeren-Keverling Buisman, A., J. M. V. M. Mouwen, T. Wensing, and H. J. Breukink. 1990. Intraruminal administration of milk in the calf as a model for ruminal drinking: Morphological and enzymatical changes in the jejunal mucosa. Vet. Res. Commun. 14:129-140.

Veissier, I., A. R. Ramirez De La Fe, and P. Pradel. 1998. Nonnutritive oral activities and stress responses of veal calves in relation to feeding and housing conditions. Appl. Anim. Behav. Sci. 57:35-49.

Welchman, D. D., and G. N. Baust. 1987. A survey of abomasal ulceration in veal calves. Vet. Rec. 121:586-590.

Žitňan, R., J. Voigt, U. Schönhusen, J. Wegner, M. Kokardová, H. Hagemeister, M. Levkut, S. Kuhla, and A. Sommer. 1998. Influence of dietary concentrate to forage ratio on the development of rumen mucosa in calves. Arch. Tierernähr. 51:279-291. 